\title{
Whence Causal Mechanisms? A Comment on Legro
}

\author{
Patrick Thaddeus Jackson and Daniel H. Nexon
}

In "Whence American Internationalism" Jeffrey W. Legro makes three important contributions to the study of international relations in general and to the development of constructivist theory in particular. First, Legro convincingly shows that the shift in American foreign policy from unilateralism to internationalism after World War II cannot be understood without reference to collective understandings about foreign policy. Second, he demonstrates that the interaction between prior intersubjective beliefs, external events, and heterodox views is an essential component of any study of ideational change. Third, Legro lucidly identifies a major problem in mainstream constructivist literature: how to theorize the translation between individual beliefs and cultural structures. This "collective ideation problem," as Legro calls it, has undermined the explanatory force of normative, ideational, and identity-based explanations for some time.

Constructivism is at an important point in its development as a research program. At the heart of constructivist theory is the idea that significant aspects of international relations are socially constructed, that is, historically contingent rather than necessary consequences of the nature of international politics. In Ian Hacking's words, social constructionism is essentially the claim that some phenomenon " $X$ need not have existed, or need not be at all as it is. $X$, or $X$ as it is at present, is not determined by the nature of things; it is not inevitable." Thus, much of the initial constructivist work in international relations sought to demonstrate that cultural (and hence putatively social and contingent) factors influence international outcomes. But it is no longer sufficient to show that "ideas" have an impact on the choices made by actors in the international arena. Instead, we need to account for

For helpful comments on earlier drafts of this article, we would like to thank Jennifer Sterling-Folker, Mark Laffey, Dan Green, Jack Snyder, Charles Tilly, and two anonymous reviewers.

Dialogue-IO

(C) 2001 by the IO Foundation and the Massachusetts Insitute of Technology 
how-and under what circumstances_-processes of social interaction centering around symbols and meaning can fundamentally transform patterns of international relations, and how these patterns impact processes of social interaction themselves. $^{2}$

In this light, Legro's latter two insights are particularly salient to constructivism. However, despite the importance of Legro's contributions to these emerging issues in constructivist theory, we have doubts about the viability of Legro's proposed “epistemic approach." Our concerns center around two issues: Legro's (implicit) reliance on functionalist reasoning and his inability to supply persuasive solutions to the collective ideation problem. We offer these concerns in the hope that they will further discussion of the problems Legro isolates in current constructivist work.

\section{From Subjective Beliefs to Cultural Structures}

In the last two decades, international relations scholars have heard a lot about the agent-structure debate. In fact, the centrality of the agent-structure problem to international relations scholarship dates back at least as far as the field's first engagements with systems theories and its early discussions of the macro-micro problem. ${ }^{3}$ Despite constructivist hostility to neorealism, Kenneth Waltz's Theory of International Politics deserves much credit (or blame) for re-igniting discussion of agent-structure issues. ${ }^{4}$

The notion that agents and structures are "mutually constitutive" is something of a cliché in constructivist theory. In contrast to structural determinists or methodological individualists, constructivists argue that individual agents and social structures not only both matter in the explanation of international outcomes, but also that the relationship between the two is reciprocal and reflexive. Given constructivist concerns with norms, identity, and ideas, this should not be surprising: the very notion of the 'social construction' of international politics implies that agents' conceptions of the world shape it and, in turn, that agents are shaped by the intersubjective structures created and sustained by their activities.

In our view, this debate is largely over; when pressed, most international relations scholars would probably agree that, from the perspective of philosophical

2. Guzzini 2000.

3. Singer 1961 .

4. Waltz 1979. 
ontology, agents and structures do not exist independently from one another. ${ }^{5}$ Even Waltz, whose work is often incorrectly invoked as an example of structural determinism, agrees with this proposition. ${ }^{6}$ The real question, therefore, is how to theorize this relationship. While it is relatively easy to assert the ontological codependency and equal importance of agents and structures, it is much harder to decide what to do with this insight. Some of these issues are abstract; others are more practical.

The options available to constructivists fall along a continuum from rigidly treating agents and structures as analytically autonomous to eschewing that autonomy in favor of starting with social processes that operate 'between' agents and structures. ${ }^{7}$ Some constructivists favor a position closer to the first end of the spectrum, which Jeffrey Alexander labels sociological "neofunctionalism." end of the spectrum, which emphasizes a focus on social transactions themselves, is sometimes called "relationalism." Anthony Giddens' structurationist solution to the agent-structure problem — a touchstone for many constructivists-falls somewhere in between the two.

The choice between approaches to the agent-structure problem probably cannot be resolved at the level of metatheory. Nevertheless, any attempt to simultaneously deal with agents and structures while giving them roughly equivalent weight is a difficult undertaking. At the same time, decisions about how to analytically resolve the agent-structure problem have concrete implications for the shape of constructivist research. Mainstream constructivists generally deploy sociological neofunctionalist accounts, in which agents and structures (whether cultural, material, or both) are treated as essentially separate levels of analysis. They attempt to gain leverage over the co-constitutive nature of agent-structure relationships by asking how agents and structures interact: How, and under what conditions, do changes at

5. A philosophical ontology refers to broad conceptions of what it means to say that something exists in the first place, whereas a scientific ontology refers to the catalog of things which are taken to actually exist in the world (Patomäki and Wight 2000). The second is the more common use for the term 'ontology' in international relations, but the first is the more fundamental theoretical issue.

6. Waltz 1979, 74-75.

7. For a more extensive treatment, see Jackson and Nexon 1999.

8. Alexander 1998. See also Nexon forthcoming. To distinguish this category from functionalist and neofunctionalist international relations theories, we will refer to it as "sociological neofunctionalism." Sociological neofunctionalism is characterized by an attention to systemic thought - usually the interaction of actor-level factors, cultural structures, and social structures-as essential to any substantive outcome, and to preserving the relative autonomy of each system.

9. See Emirbayer 1997; and Tilly 1999. 
one level influence the other level? Thus, constructivists sometimes frame their work in terms of how structural-level norms are internalized by actors, while other constructivists seek to examine how actor-level innovation influences social and cultural structures.

Ideally, these two different trajectories of interaction are combined in any single explanation of political change and outcomes. More often, constructivists produce theories that err on one side or the other. ${ }^{10}$ In consequence, constructivists "explain" the translation between agents and structures or structures and agents through assertion or empirical redescription. For instance, some show how norms diffused through a community of states or actors and how those states or actors then influenced an outcome, and then claim that structural change has taken place. ${ }^{11}$ Others focus on proxies for collective ideational phenomenon (such as public discourse or historians' judgments about the zeitgeist of a particular state or period), use them to explain some instance of behavior, and then assert that subsequent behavior somehow transformed intersubjective norms and identities.

Legro emphasizes these failures in constructivist accounts, arguing that most constructivist theories have been unable to show how microprocesses of persuasion, legitimation, and social learning translate into changes in collective beliefs. As he explains, actors seeking to change intersubjective norms of foreign policy are "challenged by collective ideation problems that make coordination difficult and/or give individuals incentives to shirk efforts to challenge dominant beliefs." 12 Legro's "epistemic approach" seeks to specify "the circumstances under which agentic arguments will be persuasive and when collective ideas" are likely to be "malleable" or "resistant in the ongoing process of mutual constitution and public argumentation." He holds that by "mating collective ideational properties and events" with the "microprocesses of collapse and consolidation" constructivists can explain these conditions. ${ }^{13}$ In this respect, his approach represents a fairly extreme form of sociological neofunctionalism, in that it treats structures and agent-level processes as highly analytically autonomous - so autonomous, in fact, that they constitute different theoretical domains that ultimately need to be synthesized.

Relationalists, on the other hand, believe neofunctionalist techniques are likely to be self-defeating. They argue that the agent-structure problem cannot be overcome by treating each level as highly autonomous. Rather than start, analytically, with agents and structures, the idea is to begin with networks of social transaction

10. Checkel 1998.

11. Tilly 1998.

12. Legro 2000, 254.

13. Ibid., 283. 
and the processes of interaction between actors. ${ }^{14}$ In this sense, social transactions are the basic building blocks of social theory, and through them one examines the interplay of actor-level decisions and social structure. The "very terms or units involved in a transaction" are constituted by the changing roles "they play within that transaction.",15

What Legro refers to as "process" accounts tend to be on the relationalist end of the spectrum. However, Legro is correct that many process accounts in international relations have been overly methodologically individualist, in that they focus on internalization, learning, and other cognitive mechanisms that are inadequate to account for transformation and continuity in intersubjective phenomena. ${ }^{16}$ Relationalists seek to shift our attention from processes "inside actors' heads" toward those that inhere in social relations between actors.

While relationalists differ on the precise nature of causal mechanisms, they agree that such mechanisms are located in the form and content of social relations, and that regularities in outcomes "take the form of recurrent causal mechanisms which concatenate differently in various settings" and that "recur in a wide variety of settings." " Some opt for an approach derived from Georg Simmel, which locates mechanisms in dynamics imminent in isomorphic but contextually embedded forms of network-configurations and their interplay with contingent, actor-level processes, adjacent processes, and historical sequence. ${ }^{18}$ Others emphasize how types of processes configure in a particular historical setting, choosing, for example, to generalize about the interaction of routine and identifiable processes not only with one another but also with temporally specific institutions. ${ }^{19}$ Nevertheless, by focusing firmly on the relations between agents and structures, the idea is to lodge causal and constitutive analysis directly in the analytical terms that provide linkage between the two.

Our position is that constructivists should adopt a more relationalist orientation that emphasizes processes of social transaction. As a well-developed sociologically neofunctionalist attempt to deal with the crucial explanatory problems that plague constructivist accounts of political change, Legro's article provides an important reference point for this debate. In fact, it is Legro's reliance upon sociological neo-

14. Jackson and Nexon 1999, 295-96, 317-18.

15. Emirbayer 1997, 287.

16. Legro 2000, 283.

17. Tilly 1999,410 .

18. Simmel 1971, 26.

19. Katznelson 1997. For those concerned with fundamental epistemology, epistemic realists may find themselves more inclined towards the former while analyticists may be inclined towards the latter. We are largely agnostic on this point. 
functionalist analytics that undermines his ability to solve the problem of linkage and provide an "aggregation mechanism" that deals adequately with the collective ideation problem. ${ }^{20} \mathrm{By}$ insisting on the rigid analytical autonomy of cultural structures and microprocesses, the "epistemic framework" cannot be married to theories of microprocesses in such a way as to genuinely explain agent-structure interaction in producing collective ideational change.

\section{The Collective Ideation Problem Has Two Faces}

The transformation of actor-level ideas into intersubjective structures has at least two dimensions, which Legro collapses into a single "collective ideation problem." The first is the more standard version of the collective action problem: How do individuals and groups mobilize in the face of coordination and free-rider problems to affect social change and challenge dominant enframings of the world? The second involves the "translation" of subjective beliefs into intersubjective ones, and is less amenable to conventional collective action explanations. Insights into the first dimension do not necessarily provide a sufficient means of explaining the second. There is, one might say, another step to the collective ideational problem manifested in its second dimension.

As Legro himself notes, collective ideational structures cannot be reduced to psychological mechanisms or the simple sharing of beliefs. ${ }^{21}$ Yet his argument does little to account for this second dimension. His theory is straightforward. In order for collective ideas to undergo rapid change, two things have to happen. First, the old orthodoxy has to be discredited. This occurs when external events defy the expectations produced and the strategies recommended by "long-held" beliefs. Thus, the failure of unilateralism to provide security (on its own terms) in the face of the events of World Wars I and II opened the way for a collective challenge to it. Second, the heterodox idea or ideas that emerge to challenge that new orthodoxy have to provide expectations and strategies that fit better with environmental conditions. If both of these happen, the probability that actors will be able to shift collective beliefs is high.

In addition, actors play an important role. The relative paucity of influential advocates for abandonment of the unilateralist orthodoxy after World War I contributed to the lack of U.S. engagement in the inter-war period. In contrast, after

20. As far as we can tell, there is no evidence that Legro relies explicitly upon sociological neofunctionalist approaches. Rather, it is the thrust of his reasoning that places the "epistemic approach" within that category.

21. Legro 2000, 264-65, 283. 
World War II supporters of heterodox foreign policy ideas were both numerous and influential. Agents at this time tossed up two heterodoxies: a "'geopolitical theory' that saw Europe as a strategic pivot" and a resurgence of quasi-Wilsonian internationalism. ${ }^{22}$ The discourse of these two conceptualizations of the U.S. role in the world were not incommensurate and provided an ideological coalition capable of providing a viable alternative to the (discredited) unilateralist orthodoxy-an orthodoxy that could not survive such devastating events as Pearl Harbor.

As an answer to the first dimension of the collective ideational problem, Legro's account prompts a number of questions. Under what conditions should we expect agents to respond to changes in structures? Even if a cultural episteme proves inadequate, how exactly do idea-entrepreneurs overcome collective action and coordination problems and promote an alternative?

For that matter, how are we to weight the relative importance of each of Legro's two steps? In World War I, Legro points out that the old orthodoxy continued to have important adherents; in World War II, it did not. Was this more or less important than the availability of plausible heterodox foreign policy ideas? We suspect that separating these factors is largely impossible. Legro himself almost seems to agree, pointing out that an orthodoxy is not likely to be "discredited" in a meaningful sense unless there is an alternative to compare it to. ${ }^{23}$ The interaction of an orthodoxy with alternative beliefs thus becomes pivotal to both supposedly discrete stages of ideational change. What additional mileage do we get from separating collective ideational change into two steps?

Whatever the problems with this first dimension, Legro's framework provides even less in the way of a solution to the second dimension. To be blunt, Legro provides no mechanisms for explaining how actor-level processes of persuasion and legitimation are converted into anything more than shared beliefs. Shared beliefs, however, are not exactly the same as intersubjective structures. For instance, take the notion of identity. The simplest way to understand the difference between shared subjective beliefs and intersubjective ones is to imagine a communication dyad between two actors (A and B). Identity is shared if A and B hold similar conceptions of 'self' and 'other' in their heads. Neither actor's identity is contingent upon the existence of the other. For example, if A and B are both democracies and hold the same norms of appropriate behavior vis-à-vis other democracies, then removing actor A from the dyad will not substantively alter B's identity: it remains inside actor B's consciousness.

22. Ibid., 271-76.

23. Ibid., 266. 
By contrast, treating identity as an intersubjective phenomenon implies that removing actor A would fundamentally alter the identity of B. Identity is intersubjective in that it is dependent upon the relationship between A and B; in fact, it would be more accurate to say that identity as an intersubjective phenomenon inheres in the relation between $\mathrm{A}$ and $\mathrm{B}$. In other words, subject-positions like "master" and "slave" have no meaning outside of the master-slave relationship (or transaction) in which they are embedded. ${ }^{24}$ To conceive of identities as relationsas intersubjective properties-requires that they be irreducible to the beliefs of any single party in a transactional setting.

Legro seeks to overcome this problem in terms of his measurement criteria: by focusing on public discourse. This prevents him from relying directly on subjective beliefs for evidence of intersubjective structures. But he uses public discourse largely as an indirect proxy for the contents of many individual heads, arguing that the President's State of the Union message is a good source of data because it is "a reasonable, easily reproducible representation of the dominant collective ideas on security policy." It is therefore an "indicator" of commonly held sentiments, a more efficient measurement than asking everyone individually. ${ }^{25}$ The problem here is that Legro treats the State of the Union message as conveying the same kind of information that a public opinion poll would: information about what is in the heads of a number of people. Thus he is not focusing on intersubjective phenomena per se, nor on any intersubjective properties (which would have to be independent of individual beliefs) which that discourse might have. ${ }^{26}$ This is rather unfortunate. A public speech is a good place to look for intersubjective phenomena, as long as it is treated as an active intervention into an ongoing process of producing and reproducing actor identities and connecting them to specific policy proposals, and not merely as a passive indicator of something that is already present in the heads of the speaker and the audience.

By treating public speech as merely a passive indicator of collective beliefs, Legro's framework risks obscuring the dynamic role public speech plays in producing political outcomes. An analyst is left to discuss the persistence and disappearance of collective notions in terms of the individual-level incentives operating against change, ignoring any causally relevant properties of those collective notions themselves, such as their location in a network of social ties or their connection to other intersubjective notions. ${ }^{27}$

24. Wendt 1998, 113-14.

25. Legro 2000, 256-58.

26. On this distinction, see Wendt 1999, 160-63.

27. As we will shortly argue, the manner in which Legro's framework incorporates the content of collective beliefs relies on functionalist reasoning. This is a direct result of treat- 
In addition, explicating the aggregate conditions for successful ideational change is not the same thing as providing an aggregation mechanism for actor-level ideas and beliefs. For this critical dimension of the collective ideation problem, Legro is forced to rely on the importation of "process" accounts. He argues that such accounts should be "mated" to the epistemic framework to provide complete explanations for ideational change..$^{28}$ This has become a common constructivist strategy of late: provide a 'structuralist' or 'agentic' account of intersubjective change and then cite theories that operate at the other level as necessary appendages of one's theory. The difficulty is that others are left to decide whether those supplementary theories are truly compatible with the structuralist or agent-level story provided by the theorist. Rather, we argue that it is incumbent upon Legro to actually provide aggregation mechanisms to specify the linkage between his structural preconditions for change and microlevel processes such as persuasion. Legro's theory focuses on the former; he also argues that such structural conditions are necessary for rapid collective ideational change. In consequence, the "epistemic approach" takes on a strong air of structural determinism: The tradeoff between the malleability and resiliency of cultural structures is wholly a product of the structures themselves. Without a theorized set of aggregation mechanisms operating between agents and structures, there is little real room for agency. ${ }^{29}$

The basic difficulty here is probably rooted deeper in Legro's assumptions. Legro adopts the sociological neofunctionalist view that, in order to give weight to cultural structures, they need to be treated as highly autonomous from actor-level processes. At first glance this makes a great deal of sense, since it analytically gives weight to the emergent properties that constitute what he calls an episteme. However, insisting on this analytical autonomy generates a "two story" problem, in that one tries to tell a "microprocessual" story focused on agents and a "macrostructural" story focused on aggregate phenomena. But that tends to mean that we can't get there from here, in that our efforts to link the two stories will generally be ad hoc. Although Legro has provided a macrostructural version of the story, he makes no real attempt to show what mechanisms impact the translation of subjective beliefs into collective ones such that they take on the emergent qualities associated with cultural structures.

ing public speeches as passive indicators of abstract epistemic structures rather than dynamic interventions in the production and transformation of intersubjective notions.

28. Legro 2000, 283.

29. A major impetus in structurationism is precisely to avoid such discrete structure-level stories on the grounds that they transform agents into "cultural dopes." See Giddens 1995, $17-18$. 


\section{Functionalism}

Legro's difficulties are both partly produced and made much more intractable by the latent functionalism of his theory. Jennifer Sterling-Folker has recently argued that neoliberal and constructivist theory is riddled with functionalist assumptions; Legro's "epistemic approach" fits her diagnosis. ${ }^{30}$

Functionalists explain the existence and/or persistence of a phenomenon by its consequences for some other phenomenon. In the context of systemic approaches, functionalist explanations analyze the stability of a system with reference to the functionality of its components. An ideology, role, or institutional arrangement is said to be functional if it fulfills the needs of the system, and to be dysfunctional if it works against those needs. For instance, the development of primary education might be said to occur because the capitalist system needs a pool of minimally trained labor in order for it to persist.

Legro argues that collective notions about a state's role in international politics are likely to persist as long as they fulfill the needs identified by those notions. Thus, unilateralism could not be effectively challenged until the strategies it recommended ceased to meet its own goals for security. Once unilateralism proved dysfunctional for those needs, heterodox ideas such as internationalism could be advanced to take its place. Internationalism could not be consolidated after World War I, however, because it proved dysfunctional for its prescribed goals (security, democracy, and so on). Only when a coalition of heterodox ideas-geopolitical theory and internationalism - that could be effectively combined emerged in an environment where external shocks had rendered unilateralism utterly dysfunctional were the collective beliefs of American foreign policy transformed. The "combinability" of these ideas, and the functionality of the resulting view of the world, seems to be wholly out of the hands of any individual. In sum, the functional integration of a cultural system itself, as well as the system's relationship to environmental factors, determines the probability of structural change.

We expect Legro to respond that he is not engaging in functional argumentation for at least two reasons: first, because he leaves some role for agency - the mating of his argument with microprocesses; second, because he derives some of his mechanisms from actor-level factors. For example, Legro draws on prospect theory's finding that "people are more sensitive to losing something than to gaining something they did not expect," and he argues that one source of failed change is "individual ignorance of others' reassessment of what is proper and desirable.",

30. Sterling-Folker 2000.

31. Legro 2000, 264-65. 
Whether his framework leaves room for microprocesses is beside the point. Legro's argument about structural sources of change derives from the functional integration of collective beliefs with external events. ${ }^{32}$ This is one reason why Legro's account can only treat actor-level processes as theoretical residuals: It is the "lens and aims of ... society itself" that is critical to determining agents' expectations and behaviors. ${ }^{33}$ The degree to which those collective beliefs are functional with regards to culturally-determined expectations and external events becomes the necessary condition for rapid change. Hence Legro's logic is functionalist.

The second potential defense is also problematic. Functionalist explanations work quite well in the context of identifiable feedback loops where two phenomena exist in a relationship of mutual reinforcement. ${ }^{34}$ Once Legro invokes prospect theory, he moves within two paragraphs to language such as "the more a society encounters events connected in substance and time that defy expectations with some negative results, the more likely will collapse occur. ${ }^{35}$ But societies are not individuals. They do not have needs or expectations. At best, corporate entities may be analytically treated as actors only if their structures produce processes that are plausibly analogous (or metaphorically similar) to mental ones. Mechanisms derived from structures, therefore, should not rely on the imputation of "needs" or other "requirements" but rather on the identification of how the form and content of structure produce specific enabling and constraining effects on agents. Systems and societies do not have needs: "Not even the most deeply sedimented institutional features of society come about, persist, or disappear because those societies need them to do so." ${ }^{, 36}$

Nevertheless, Legro's form of functionalist reasoning may be acceptable when deployed to produce a counterfactual argument:

We can quite legitimately pose conjectural questions such as: "What would have to be the case for social system $x$ to come about, persist, or be transformed?" But we have to be very careful with such propositions, because they readily lend themselves to interpretation in a functionalist mode. "In order to persist in a relatively stable form, the capitalist economy has to maintain a certain over-all level of profit." The force of the "has to" here is counterfac-

32. No systemic functionalist ever denied a room for agency; rather, functionalists argue that agent-level factors need to be combined with (functionalist) system dynamics to produce concrete outcomes. See Alexander 1998.

33. Legro 2000, 267.

34. Stinchcombe 1968.

35. Legro 2000, 265.

36. Giddens 1995,18 
tual: it involves identifying conditions that must be met if certain consequences are to obtain. The "has to" is not a property or "need" of the system. ${ }^{37}$

If Legro is simply developing a counterfactual, then he is on stronger ground. His work would then suggest a research agenda that looks for social mechanisms of persuasion and legitimation and shows how actors rhetorically deploy particular events in a political context to bring about changes in others' beliefs and behavior. Legro seems to suggest something along these lines toward the end of his article. ${ }^{38}$ Unfortunately, throughout most of the article Legro treats his theory not as a counterfactual but as an actual explication of processes and mechanisms of ideational change. ${ }^{39}$

As a result, Legro's argument borders very close to tautology: changes in ideational structures happen when old ones become discredited and new ones emerge that can take their place. But when would this not be the case? By definition, there cannot be changes in "long-held" collective notions unless an orthodoxy is discredited and a new one emerges that can take its place. Arguing that an orthodoxy is likely to be discredited when events disconfirm its image of the world is to state a truism. When would an orthodoxy be discredited without these conditions? It might be possible that a set of beliefs could be so internally contradictory as to make them ripe for change, but the development of such internal contradictions probably wouldn't occur without the effects of external events. The reason Legro's argument appears generalizable is because of its tautological qualities-it explains the broad structural conditions necessary for any change in collective ideas. And what Legro fails to do is to provide an answer to the more fundamental question: how do events "disconfirm" an orthodoxy?

These factors also result in a strong teleological flavor. To his credit, Legro fully admits this, stating that his method "minimizes (but does not eliminate) the inherent danger of measuring 'causes' by effects in historical analysis." ${ }^{40}$ Yet we are not convinced that he has really minimized this danger; after all, by Legro's argument, why didn't internationalism succeed as a result of World War I? Because events surrounding World War I failed to convince policy making elites that internationalism was an appropriate orthodoxy for American foreign policy. As long as this failure to convince-which Legro sometimes refers to as the "fit" between outlooks and events-is left untheorized, the causal logic is left largely unspecified. In short, we risk the post hoc, ergo propter hoc fallacy.

37. Ibid., 18-19.

38. Legro 2000, 281-84.

39. Ibid., 281.

40. Ibid., 267. 


\section{Relationalist Accounts}

We believe that explanatory frameworks in a more relational mode-such as the "process" accounts Legro criticizes—are better suited to answer these questions, as they allow for the development of robust aggregation mechanisms. When one rigidly treats cultural structures as analytically autonomous from actor-level processes, it is rather easy to slide into functionalist accounts of the conditions necessary for actors to transform structures precisely because any specification of when structures will be vulnerable or resistant to change involves imputations about the needs of a structure to maintain itself. ${ }^{41}$ In Legro's case, the resultant "fallacy of misplaced concreteness" takes an extreme form in that he imputes modified mental qualities to cultural structures. Thus he begs the question of how agents and structures are actually linked through processes of ideational change.

When exogenous events defy the expectations prescribed by their roles and ideas, it is actors who experience dissonance and innovate to develop heterodox notions. From a relationalist perspective, these constitute "shocks" to the preexisting network of social ties; they are perturbations in what had previously been stable transactional flows linking actors. ${ }^{42}$ Theories of structural change are specifications of the conditions under which potential shocks will be absorbed by sociocultural networks, or will aggregate to produce lasting alterations in modes of relating. Legro's theory covers the most straightforward of such conditions: when the challenge to role expectations is so severe and widespread that a critical mass of actors in the network experience dissonance. When this happens, actors innovate by drawing upon preexisting heterodoxies or combining available roles to produce novel configurations of beliefs and identities. Since the shock is widespread, there exists a good probability that some new orthodoxy will emerge.

However, in order to know if this is true for the cases at hand, we need to engage in careful empirical analysis of precisely where heterodox ideas emerged in a network, where they spread to, and what processes of legitimation and persuasion took place at various critical locations. Large-scale shocks may not result in structural change, even if they appear to disconfirm intersubjective beliefs. On the other hand, large-scale shocks may not be necessary for rapid structural change. Aggregate effects may result from contingent alterations in local networks if they "tip" the entirety of social relations. For instance, they may switch, or even reconfigure, a set of ideological ties that are critical to the structure of the network, making key

41. Giddens 1995, 19.

42. Even in the case of rapid transformation in aggregate network configurations, shocks need not be exogenous. See Bearman et al. 1999. 
alliances between actors unsustainable. Regardless, theories that explore such circumstances require analysis of the relationship between specific political processes and patterns of transaction or the relational interdependencies of ideational networks. ${ }^{43}$ Mechanisms operating at this level provide the crucial link between external "events" and the "reactions" of various actors embedded within a network. ${ }^{44}$ Such mechanisms deal directly with intersubjective phenomena, since they operate in the public ${ }^{45}$ space outside of anyone's head. For example, John Padgett and Christopher Ansell have argued that "robust action" and multivocal projections of identity are critical to effective control and mobilization in segmented social networks; what is central to the explanation is the relationship between network patterns and strategies, not between beliefs and behaviors. ${ }^{46}$

Given the constrained space of this forum, we can only provide a sketch of an alternative account to Legro's. ${ }^{47}$ To begin with, rather than dichotomize American foreign policy beliefs into "unilateralist" and "internationalist" ones, we need to pay close attention to the multiple networks of beliefs and their relationship to one another. Not all "internationalists" today or historically are the same; many deploy different arguments on behalf of different levels and kinds of involvement with international institutions and foreign countries. When we pay closer attention to the specifics of the arguments advanced by the opponents and proponents of particular policy proposals, it becomes clear that "unilateralism" and "internationalism," whatever their analytical utility as ways of categorizing policies, do not reflect the contours of the debates about those policies very well. Each policy option is instead supported and opposed by a constellation of rhetorical commitments that often do not utilize these terms at all. We should note that we are not arguing that the analysis of policy articulation should always confine itself to using the terms and arguments preferred by historical actors themselves. We are instead suggesting that it is difficult, if not impossible, for terms and arguments not present in a policy debate to have a significant causal impact on the debate's outcome.

"Unilateralism" as a policy position consists of at least two rhetorical "commonplaces" ${ }^{48}$ on which advocates of unilateralist policies drew in attempting to

43. Formal network models have generated a number of interesting hypotheses that we do not have space to discuss here. See, for example, Kim and Bearman 1996.

${ }^{44}$ This is, perhaps, our crucial difference with Legro. Legro's approach relegates these concerns to the microlevel and treats intersubjective structures as abstract sets of ideas.

45. "Public" here need not mean widely publicized or even accessible to a great many people. It simply means that relational patterns are not under the control of any one individual, but take place "between" them.

46. Padgett and Ansell 1993.

${ }^{47}$ For a more extensive treatment, see Jackson 2001.

48. On "commonplaces," see Shotter 1993, 68-69, 136-38. 
advance their position. The most prominent commonplace might be called "American exceptionalism," which is the notion that America represents a different kind of political community from others, specifically those in Europe. This distinction is absolute, and advises that American foreign policy should retain a "prelapsarian" character, "intent upon preventing the original sin of a balance of power from being committed in North America." ${ }^{49}$ Another commonplace might be called "heliotropism," the notion that civilization progresses inexorably in a westward direction (following the path of the sun). This commonplace gives rise to the notion that the United States represents a better kind of political community than others, specifically those in Europe, and should concentrate its efforts on working out its "manifest destiny" undisturbed, as a "city on a hill." ${ }^{\text {.50 }}$ It is important to keep in mind that these commonplaces do not necessitate unilateralist policies, but that their combination provides rhetorical resources for anyone wishing to advocate such policies.

Opponents of these policies needed to address arguments that drew on these commonplaces, which they did by assaulting American exceptionalism and trying to turn heliotropism to their benefit by severing its link to that exceptionalism. Different "internationalists" attempted to do this in different ways. Woodrow Wilson tried to use heliotropism to link exceptionalism to an American responsibility to lead the world on towards salvation, whereas both Roosevelts were inclined to try to "normalize" the United States by bringing it into a community of "civilized" powers, albeit as the most "civilized" of the group. ${ }^{51}$ After World War II, advocates of internationalist policies could draw on another commonplace, "occidentalism," in pursuit of their goals. Occidentalism maintained that the United States participated in a larger cultural community (often referred to as "Western Civilization") of like-minded states and could not, for this reason, remain completely detached from them. It therefore had a responsibility to preserve the other members of the community, and particularly to preserve their democratic forms of government. ${ }^{52}$

In order to explain shifts in U.S. policy, it is necessary to examine the ways in which these rhetorical commonplaces-which were of course embedded in and exemplary of a variety of concrete social ties and institutions-interacted with one another, and with other commonplaces such as "anticommunism" that had been fixtures of the discursive landscape for quite some time. How specific people located at key positions combined these arguments, and the specific policy consequences that they drew from them, exercised a significant impact on U.S. policy.

49. See Boorstin 1960, 19-25; and Ninkovich 1994, 46.

50. See Schulte Nordholdt 1995, 1-2; Stephanson 1995, 18-20; and Baritz 1964.

51. See Stephanson 1995, 114-15; Ruggie 1998, 207-209; and Harper 1994, 73-76.

52. See Risse-Kappen 1996, 370-71; Coker 1998, 19-20, 122-26; and Schulte Nordholt, 204-206. 
The "fit" of particular notions with external situations depends in no small measure on the ways in which that external situation is interpreted in the first place; this in turn depends on the subtle contours of the rhetorical commonplaces available for the making of socially sustainable arguments, and how they are combined in practice.

During World War I, there were two external events that created perturbations in the American ideational matrix: American participation in a European land war, and the Russian revolution. American internationalists failed in large part because there were few rhetorical strategies available to link domestic fear of and opposition to communism-which was at least in part fueled by the occurrence of the Russian revolution - to a policy of multilateral global engagement. In fact, to the opponents of the latter, anticommunism seemed to point in precisely the opposite direction: to a renewed withdrawal from the world for the sake of internal purification. The meaning of the Russian revolution was constructed through deployments of the commonplaces of American exceptionalism and heliotropism to produce a policy recommendation in favor of remaining aloof from the world and securing the borders of the United States against the communist contagion. This policy was graphically illustrated in the mass deportation and expulsion of communists arrested during the Palmer raids in $1919 .{ }^{53}$

In World War II, by contrast, there had emerged a network of political actors linked by an ideological commitment to the notion that the United States was part of a larger community, including Western Europe, which they called "Western Civilization." In the United States, this network included George Marshall, Dean Acheson, and George Kennan; it had counterparts among European elites such as Ernest Bevin and Konrad Adenauer. It is this shared rhetorical commitment that permitted these elites to persuasively link anticommunism with American multilateral global engagement. Communism could be understood and portrayed as a threat not simply to some discrete notion of American domestic liberalism, but as an assault on the core values of Western Civilization itself. The key point here is not simply that anticommunism provided support for an internationalist policy, but that it did so because of alterations in the discursive resources available to "internationalists," alterations which subtly shifted the meaning and the policy implications of anticommunism itself. Legro is correct to note that important voices in the United States had shifted to advocating internationalist policies before a clear Soviet threat had emerged ${ }^{54}$ but anticommunism as a rhetorical commonplace and constitutive element of American national identity precedes the Cold War by at least several

53. See Stephanson 1995, 116-19; Kovel 1994, 17-22; and Leffler 1994, 14-15.

54. Legro 2000, 255, 273-75. 
decades. How it was combined with other commonplaces in the course of policy debates is a crucial part of the explanation for shifts in U.S. policy.

Using this new rhetorical strategy, Marshall and his allies-situated with the power of the executive branch behind them-engaged in a massive political propaganda campaign to reconfigure American political discourse to indelibly link anticommunism to the defense of Europe. Given that "unilateralist" discourse depended on the essential separateness of America from the rest of the world and the defense of its core values, this strategy effectively severed the connection between the preservation of core American values and the physical boundaries of the United States. America henceforth could only be defended at the borders of Eastern Europe, and perhaps beyond that. ${ }^{55}$ In the absence of this severing of the isolationist ideational matrix, there is good reason to believe that collective ideational structures would have been relatively resilient in the fact of external shocks. Immediately after World War II, for example, the United States demobilized an overwhelming majority of its troops, suggesting that "internationalism" may not have been as firmly established in the early postwar period as Legro suggests. ${ }^{56}$ The American role in the world was interpreted very differently; had this interpretation remained dominant, the consequence might have been a much smaller U.S. internationalist commitment, one that perhaps eschewed the stationing of U.S. troops abroad. ${ }^{57}$ The Truman Doctrine and the European Recovery Program, for example, represent explicit attempts to address this concern by providing an alternative, "internationalist" interpretation based on the United States' responsibility to defend the other members of what George Marshall in testimony before Congress referred to as "Western civilization, of which we are by belief and inheritance an integral part." $" 58$

Wilson had no such intersubjective scripts available to him. Thus, the apparent failures of Versailles could only be read as evidence that the rest of the world was corrupt and that the United States needed to isolate itself, while two decades later similar events and the historical experience of Versailles could be reinterpreted as evidence of the necessity of U.S. engagement to shore up Western Civilization. Why were no such scripts available during World War I? This is because there were two primary sources for them, and these sources were not in evidence until the interwar period. First, there was the War Issues Course developed by Columbia

55. Ninkovich 1994, 117-18. Much of the early Cold War was about determining precisely where this boundary lay.

56. See the figures in Pollard 1985, appendix.

57. Ibid., 223.

58. See Ninkovich 1994, 171-73; Leffler 1992, 144-46; and U.S. Department of State $1948,71$. 
University and the War Department to justify American involvement in World War I. After that conflict, the course was preserved, both at Columbia and at a plethora of other American colleges and universities, as the "Western Civ" course. The generation of elites trained in this course and the civilizational scripts that it disseminated did not come into power until well after the events at Versailles. ${ }^{59}$ Second, the "civilizational" interpretation of world history—disseminated by such thinkers as Oswald Spengler and Arnold Toynbee, and partially revolving around their interpretation of the significance of World War I-became a prominent part of the American cultural milieu in the interwar years, fueled by the immense popularity of Spengler's book and, later, by Toynbee's public lectures. ${ }^{60}$

Contrary to Legro, these developments were not simply "microprocesses" but constituted subtle shifts in the matrix of American intersubjective identity. Thus, the ideational networks in existence during and after World War II were significantly different from those preceding World War I for reasons not merely ascribable to the interaction of exogenous shocks with collective beliefs. Different underlying political and ideational patterns would have produced different outcomes even in face of the same external shocks and the same general collective beliefs. It is not simply the "availability" of a better heterodoxy that explains American internationalism, but the concrete ways in which the diffusion of specific ideas altered extant political and ideological networks to make them ripe for transformation. These changes directly affected the opportunities and costs associated with collective ideational action, but without determining a unique equilibrium point. It is possible to imagine many sources of failure that could have altered outcomes significantly. Actors could have failed to activate the ideological and political resources made available to them by the networks in which they were embedded and thus failed to transform them. Other actors could have developed different rhetorical strategies out of this material that were more effective at countering the "internationalists." A robust empirical analysis would have to examine these factors in much greater detail. The point is that these processes of intersubjective transformation are themselves causal, and do not function merely as "intervening variables" to transmit the effects of external shocks to some renewed functional integration of the system.

To the extent that Legro's account is compatible with the one we have suggested, it is because Legro's analysis operates at a level of abstraction close to tautology. In fact, this level of abstraction raises the question of whether Legro's account is even competitive with that offered by neorealists. From a Waltzian per-

59. Levine 1996, 59-64.

60. See McNeill 1989, 211-2; and Hughes 1952, 89-96. 
spective, Legro's arguments simply document the process of socialization experienced by great powers in the international system. Over time, great powers that shirk from protecting their interests by balancing against potential rivals (internally and through alliance politics) will either be forced to conform by external events or be selected out of the system. ${ }^{61}$ The fact that decisive U.S. international commitments did not appear for some time is not inconsistent with neorealist claims that socialization and competition effects are structural pressures without determinate effects in any particular instance. In this reading, what Legro provides is an exploration of how these factors work within a domestic system. Regardless, we believe that disaggregating structures into concrete and empirically observable networks of social transaction will provide more useful and falsifiable accounts of intersubjective change. It is the very process accounts that Legro sees as mere appendages to his epistemic approach that provide better building blocks for such an endeavor.

\section{References}

Alexander, Jeffrey, ed. 1998. Neofunctionalism and After. Oxford: Blackwell.

Baritz, Loren. 1964. City on a Hill: The History of Ideas and Myths in America. New York: Wiley.

Bearman, Peter S., Robert Faris, and James Moody. 1999. Blocking the Future: New Solutions for Old Problems in Historical Social Sciences. Social Science History 23 (4):501-33.

Boorstin, Daniel J. 1960. America and the Image of Europe. New York: Meridian Books.

Checkel, Jeffrey T. 1998. The Constructivist Turn in International Relations Theory. World Politics 50 (2):324-48.

Coker, Christopher. 1998. Twilight of the West. Boulder, Colo.: Westview Press.

Emirbayer, Mustafa. 1997. Manifesto for a Relational Sociology. American Journal of Sociology 103 (2):281-317.

Giddens, Anthony. 1995. A Contemporary Critique of Historical Materialism. 2d ed. Stanford, Calif.: Stanford University Press.

Guzzini, Stefano. 2000. A Reconstruction of Constructivism in International Relations. European Journal of International Relations 6 (2):148-82.

Hacking, Ian. 1999. The Social Construction of What? Cambridge, Mass.: Harvard University Press.

61. Waltz 1979. 
Harper, John Lamberton. 1994. American Visions of Europe: Franklin D. Roosevelt, George F. Kennan, and Dean G. Acheson. Cambridge: Cambridge University Press.

Hughes, H. Stuart. 1952. Oswald Spengler: A Critical Estimate. New York: Charles Scribner's Sons.

Jackson, Patrick Thaddeus. 2001. Occidentalism: Rhetoric, Process, and Postwar German Reconstruction. Ph.D. diss., Columbia University.

Jackson, Patrick Thaddeus, and Daniel Nexon. 1999. Relations Before States: Substance, Process, and the Study of World Politics. European Journal of International Relations 5 (3):291-332.

Katznelson, Ira. 1997. Structure and Configuration in Comparative Politics. In Comparative Politics: Rationality, Culture, and Structure, edited by Mark Irving Lichbach and Alan S. Zuckerman, 42-80. Cambridge: Cambridge University Press.

Kim, Hyojoung, and Peter S. Bearman. 1997. The Structure and Dynamics of Movement Participation. American Sociological Review 62 (1):70-93.

Kovel, Joel. 1994. Red Hunting in the Promised Land: Anticommunism and the Making of America. New York: Basic Books.

Leffler, Melvyn. 1992. A Preponderance of Power: National Security, the Truman Administration, and the Cold War. Stanford, Calif.: Stanford University Press.

- 1994. The Specter of Communism: The United States and the Origins of the Cold War, 1917-1953. New York: Hill and Wang.

Legro, Jeffrey W. 2000. Whence American Internationalism. International Organization 54 (2):253-89.

Levine, Lawrence W. 1996. The Opening of the American Mind: Canons, Culture, and History. Boston: Beacon Press.

McNeill, William H. 1989. Arnold J. Toynbee: A Life. New York: Oxford University Press.

Nexon, Daniel. Forthcoming. Which Historical Sociology? Review of International Studies.

Ninkovich, Frank A. 1994. Modernity and Power: A History of the Domino Theory in the Twentieth Century. Chicago: University of Chicago Press.

Padgett, John F., and Christopher K. Ansell. 1993. Robust Action and the Rise of the Medici, 1400-1434. American Journal of Sociology 98 (6):1259-1319.

Patomäki, Heikki, and Colin Wight. 2000. After Postpositivism? The Promises of Critical Realism. International Studies Quarterly 44 (2):213-37.

Pollard, Robert A. 1985. Economic Security and the Origins of the Cold War, 1945-1950. New York: Columbia University Press.

Risse-Kappen, Thomas. 1996. Collective Identity in a Democratic Community: The Case of NATO. In The Culture of National Security: Norms and Identity in World Politics, edited by Peter J. Katzenstein, 357-99. New York: Columbia University Press. 
Ruggie, John Gerard. 1998. Constructing the World Polity: Essays on International Institutionalism. London: Routledge.

Schulte Nordholt, Jan Willem. 1995.The Myth of the West: America as the Last Empire. Grand Rapids, Mich.: Eerdmans.

Shotter, John. 1993. Cultural Politics of Everyday Life: Social Constructionism, Rhetoric, and Knowing of the Third Kind. Toronto: University of Toronto Press.

Simmel, Georg. 1971. On Individuality and Social Forms: Selected Writings. Edited by Donald N. Levine. Chicago: University of Chicago Press.

Singer, J. David. 1961. The Level-of-Analysis Problem in International Relations. In The International System: Theoretical Essays, edited by Klaus Knorr and Sidney Verba, 77-92. Princeton, N.J.: Princeton University Press.

Stephanson, Anders. 1995. Manifest Destiny: American Expansionism and the Empire of Right. New York: Hill and Wang.

Stinchcombe, Arthur L. 1968. Constructing Social Theories. New York: Harcourt, Brace, and World.

Sterling-Folker, Jennifer. 2000. Competing Paradigms or Birds of a Feather? Constructivism and Neoliberal Institutionalism Compared. International Studies Quarterly 44 (1):97-119.

Tilly, Charles. 1998. International Communities, Secure or Otherwise. In Security Communities, edited by Emanuel Adler and Michael Barnett, 397-412. Cambridge: Cambridge University Press.

- 1 1999. Epilogue: Now Where? In State/Culture: State Formation After the Cultural Turn, edited by George Steinmetz, 407-20. Ithaca, N.Y.: Cornell University Press.

U.S. Department of State. 1948. Assistance to European Economic Recovery. Statement of George Marshall before the Senate Committee on Foreign Relations, 8 January 1948. Department of State Bulletin 18:71-77.

Waltz, Kenneth N. 1979. Theory of International Politics. New York: McGrawHill.

Wendt, Alexander. 1998. On Constitution and Causation in International Relations. In The Eighty Years' Crisis: International Relations 1919-1999, edited by Tim Dunne, Michael Cox, and Ken Booth, 101-17. Cambridge: Cambridge University Press.

—. 1999. Social Theory of International Politics. Cambridge: Cambridge University Press 